\title{
The Relationship between Occupational Stress and Job Satisfaction: The Case of Pakistani Universities
}

\author{
Abdul Qayyum Chaudhry \\ Assistant Professor, Institute of Education \& Research \\ University of the Punjab, Quaid - e - Azam Campus, Lahore, Pakistan \\ E-mail: Qayyum.ier@pu.edu.pk
}

Received: December 30, 2011 Accepted: January 9, 2012 Published: May 21, 2012

doi:10.5539/ies.v5n3p212

URL: http://dx.doi.org/10.5539/ies.v5n3p212

\begin{abstract}
This paper aims to find out the relationship between occupational stress and job satisfaction based on age, gender, nature of job, cadre, work experience of university teachers, and sector of university. The Pearson correlation indicates: no significant relationship found between job satisfaction and overall occupational stress; inverse relationship is found between the occupational stress and overall job satisfaction in faculty members of private universities; is no relationship between the occupational stress and overall job satisfaction in faculty members of public universities; no relationship between the occupational stress and overall job satisfaction in case of both male and female faculty members of universities; young age university teachers are more sensitive to the occupational stress and job satisfaction; and no significant relationship is found between the occupational stress and overall job satisfaction in faculty members of universities across the nature of job; visiting, contract and permanent.
\end{abstract}

Keywords: Occupational stress, Job satisfaction, Demographics, Universities

\section{Introduction}

The developing countries are in transitional phase of development, newly exposed to economic integration and started experiencing workforce diversity to larger extent. Higher education sector is among the highly influenced sectors of this transition and takes major responsibility to direct the nation towards right path. Universities primarily play the role of promoting research and development, enhancing teaching capacity and developing management discipline in the countries. The faculty of universities promises to meet this great challenge of attaining objectives of higher education, which resultantly puts high stress on them. The stress bearing capacity is backed by their level of satisfaction to the institutions. The highly stressed and poorly satisfied faculty cannot help the universities to compete such global challenges. The universities in Pakistan and other countries particularly of developing nations need to adopt continuous job satisfaction and occupational stress assessment programs and investigate their causal relationship. In Pakistan higher education is dominated by two sectors: private and public. The open market policy has encouraged now to bring foreign universities to enter into Pakistani market. The competition has changed from bare buildings and enrolment to faculty, programs, contents, academic sources and reputation of institutes. The success of universities in near future will highly depend on the capacities and performance of their faculty. Due to the service oriented nature of the job, faculty of universities is in direct contact with graduates/customers, and highly satisfied faculty with low level of stress can produce stratified graduates and make long-term impact on university branding.

Moorhead and Griffin (2001) stated that "stress is caused by a stimulus, that the stimulus can be either physical or psychological, and that the individual responds to the stimulus in some way. Here, we define stress as a person's adaptive response to a stimulus that places excessive psychological or physical demands on him or her". Fleet Van (1991) has successfully tried to compose the various definitions of stress into single meaningful definition that "stress is a person's adaptive response to excessive psychological or physical demands caused by some stimulus". Occupational stress is the result of individuals to know alarming issue in their work environments. Obviously, it is stress on the job that occurs in a person. The worker when involved in problem, bring occupational stress as result (Arnold and Feldman, 1986). In the case of university teachers, the occupational stress is described as "university teaching is consistently reported to be a satisfying profession by its practitioners being a professor is accompanied by a certain trait with low occupational stress” (Greenberg, 2002). 
Occupational stress and job satisfaction among university teachers is direly needed to improve the quality of education. Since various studies across the globe have referred that stress and job satisfaction of faculty members affect their performance, productivity, efficiency and effectiveness. It is worthwhile to find out the relationship between these two variables to improve the quality of education at university level. Spector (1997) reported that the high level of job satisfaction leads to higher teaching performance and better learning outcome, which disproportionately relates to job stress. Satisfaction among faculty reported as one of the remedial measures of job stress and attracted the attention of educationists. Number of reasons described such as utilitarian, humanitarian, and organizational effectiveness for the need of job satisfaction in university faculty. Job satisfaction indicates fair treatment, mutual respect; better functioning that positively influences performance of university teachers.

\subsection{Statement of Problem}

The impact of occupational stress on job satisfaction is examined in various business and social sectors across the world. This relationship in the university settings of Pakistan is missing in the literature. The study is designed to investigate the relationship between occupational stress and job satisfaction based on demographic variables like gender, sector, cadre, age, nature of job and length of service in Pakistani universities.

\subsection{Purposes of the Study}

This paper aims to find out the relationship between occupational stress and job satisfaction in Pakistani universities based on age, gender, nature of job, cadre, work experience of university teachers, and sector of university.

\subsection{Significance of the Study}

Research studies have widely discussed about the relationship between occupational stress and job satisfaction of teachers. The work done in this regard covers broad range of disciplines like elementary and secondary education, but less attention is paid to higher education with respect to teacher satisfaction and job stress. The developing country like Pakistan, where literacy rate is very low, resources are limited, and very little percentage of students reach to the university level. It requires imperative attention of higher management towards teaching system and faculty assigned to impart the promised knowledge. The faculty members as front-line players in the entire value-chain of universities carry greater responsibility, and play a significant role in overall institutional success. The satisfied faculty can help the university to achieve its desire goals and meet the educational objectives. Contrarily, teachers' high level of job stress creates the big gap between promised and actual levels of educational quality. The scenario raises the need for a comprehensive study, to investigate the relationship between occupational stress and job satisfaction of university teachers.

\subsection{Organization of the Study}

In this study, introduction is pronounced in section 1; review of literature is explained in section 2; hypotheses of the study are described in section 3; research methodology is illuminated in section 4; results are interpreted in section 5; conclusions are clarified in section 6; limitations and delimitations of the study are discussed in section 7; and future research gap is defined in section 8 of the study.

\section{Literature Review}

Berger (1981), as cited in (Duke, 1990), conducted a study on job stress and found that job stress caused by broad range of tasks and responsibilities that divert teachers from their primary functions rather than mere professional duties, in American teachers.

Williams and Wiatrek (1986) conducted study in order to know the job satisfaction level of faculty members both full time and part time. He found that communication flow and extent between part-time and full-time faculty members also formulate good level of faculty satisfaction; however, no significant relationship is reported between both; part-time and full-time faculty members.

Wisniewski (1990) conducted a study in response to the number of issues related to faculty job satisfaction is raised in academic conversation such as to what extent teacher is satisfied, relevancy of work with teacher's own desire, opportunity cost of being a teacher, likes and dislikes of work characteristics and overall perception towards teaching profession. He found some important factors such as: competitive pay scale, smooth working conditions, pleasant institutional culture and rooms for new experiments, and improvements.

Robbins (1996) conducted a study while examining the occupational stress and job satisfaction. He found the relationship between job satisfaction and occupational stress is also moderated by number of factors like relevant placement, clarity of job role, level of responsibility and designated power. Factors like job importance, uniformity, autonomy and identity improve the job satisfaction, while low level of empowerment, less control over work and unfair interference of higher management increase stress and overall dissatisfaction. 
Wu, et al. (1996) studied the association between various factors with job satisfaction the result of the study reflects, that self-efficacy and professional growth are significantly related with job satisfaction, while commitment is also significantly related with self-efficacy, professional growth and status of that job.

Truell et al. (1998) conducted study in order to explore the dimensions of job satisfaction of faculty members. He found satisfaction dimensions such as execution, responsibility, administration, and functional environment. Further, he reported significant variance in satisfaction of part-time and full-time regarding various external aspects, and these results were contrast to the findings of Williams and Wiatrek (1986) study.

Rocca and Kostanski (2001) have attempted to study the relationship of burnout and job satisfaction and concluded "employment status does not impact too greatly on the issues of job satisfaction and burnout. However, certain facets of job satisfaction (i.e. operating conditions, nature of work and rewards) across all employment status groups influence components and levels of burnout within secondary teaching”.

Fatima (2003) conducted study in order to measure the trends adopted in satisfaction studies of university faculty indicate a change from mare employee satisfaction with reference to various factors such as more exploring significant relationship of interpersonal satisfaction, work group satisfaction, overall competition level satisfaction, profession and career satisfaction.

Sattar and Jamil (2004) conducted a research study to find out the effects of stress on job satisfaction of head teachers at elementary level. Sample of the study were thirty heads (fifteen male and fifteen female) of elementary schools of Lahore city. The results of the study show that most of the head teachers at elementary level are in stress and it is negatively affecting their job satisfaction. In some cases, females are more stressed and in some the male heads are more stressed decreasing their level of job satisfaction.

Togia et al. (2005) conducted study and reported the deficiency of literature in treating job satisfaction and burnout as a dimensional approach. Therefore, considerations for individuals work condition, which contribute to burnout, satisfaction is needed, and multivariate approach is suggested to understand their associations.

\section{Hypotheses of the Study}

$\mathrm{H}_{01}$ There is no significant relationship between job satisfaction and occupational stress.

$\mathrm{H}_{01.1}$ There is no significant relationship between job satisfaction and occupational stress in case of faculty in private universities.

$\mathrm{H}_{01.2}$ There is no significant relationship between job satisfaction and occupational stress in case of faculty in public universities.

$\mathrm{H}_{01.3}$ There is no significant relationship between job satisfaction and occupational stress in case of male faculty of universities.

$\mathrm{H}_{01.4}$ There is no significant relationship between job satisfaction and occupational stress in case of female faculty of universities.

$\mathrm{H}_{02}$ There is no significant relationship between job satisfaction and occupational stress in case of lecturers of universities.

$\mathrm{H}_{02.1}$ There is no significant relationship between job satisfaction and occupational stress in case of assistant professors of universities.

$\mathrm{H}_{02.2}$ There is no significant relationship between job satisfaction and occupational stress in case of associate professors of universities.

$\mathrm{H}_{02.3}$ There is no significant relationship between job satisfaction and occupational stress in case of professors of universities.

$\mathrm{H}_{03}$ There is no significant relationship between job satisfaction and occupational stress in case of 20-30 years old faculty of universities.

$\mathrm{H}_{03.1}$ There is no significant relationship between job satisfaction and occupational stress in case of 31-40 years old faculty of universities.

$\mathrm{H}_{03.2}$ There is no significant relationship between job satisfaction and occupational stress in case of 41-50 years old faculty of universities.

$\mathrm{H}_{03.3}$ There is no significant relationship between job satisfaction and occupational stress in case of 51-60 years old faculty of universities. 
$\mathrm{H}_{03.4}$ There is no significant relationship between job satisfaction and occupational stress in case of above 60 years old faculty of universities.

$\mathrm{H}_{04}$ There is no significant relationship between job satisfaction and occupational stress in case of $0-3$ years experienced faculty of universities.

$\mathrm{H}_{04.1}$ There is no significant relationship between job satisfaction and occupational stress in case of 4-12 years experienced faculty of universities.

$\mathrm{H}_{04.2}$ There is no significant relationship between job satisfaction and occupational stress in case of 13-20 years experienced faculty of universities.

$\mathrm{H}_{04.3}$ There is no significant relationship between job satisfaction and occupational stress in case of 21 \& above years experienced faculty of universities.

$\mathrm{H}_{05}$ There is no significant relationship between job satisfaction and occupational stress in case of visiting faculty of universities.

$\mathrm{H}_{05.1}$ There is no significant relationship between job satisfaction and occupational stress in case of contract faculty of universities.

$\mathrm{H}_{05.2}$ There is no significant relationship between job satisfaction and occupational stress in case of permanent faculty of universities.

\section{Research Methodology}

The relationship between job stress and job satisfaction has attained high attention in academic literature. The recent developments in higher education of Pakistan require attention of academic researchers on various issues such as job satisfaction and relationship with job stress. This study aims to analyze the relationship between occupational stress and job satisfaction of faculty universities in Pakistan. For this purpose, the views of faculty of universities in three big cities of Punjab are collected. The adapted versions of standardized instruments are used with necessary modification to elicit the job stress and job satisfaction level of university teachers and their relationship under various settings. Numbers of demographical variables are included in both instruments to see the association and relationship across the various independent attributes. The overall scheme of research was designed through the extensive literature review; consultations with experts, direction and guidance of supervisor carried out according to recommendations of doctoral committee, board of studies, and advanced board of studies.

In order to measure occupational stress of university teachers, the commonly used professional life stress scale adapted by Fontana (1989) from The British Psychological Society and Routlegde London. Researcher with necessary modifications according to local settings uses the same instrument. The instrument of stress includes 24 test items and constitutes an overall stress score. The test has standardized methods as people score 01-15 falls under "low stress", 16-30 fall "under moderate stress", and scorers between 31-45 are in "existent of high stress" and people scoring 45-60 are in "serious stress" category. The adapted versions of standardized instruments are used with necessary modification to elicit the job stress level of university teachers. Demographic variables were also included in instruments.

The study develops an estimate of six universities of Punjab, a province of Pakistan, comprised of three public and three private universities. Five hundred (500) university teachers were included in the sample, including 150 of private and 350 of public universities. Five hundred targeted respondents were considered quite reasonable and highly representative of the university settings. From the 500-targeted sample, 310 responses of both universities private (78) and public (232) were achieved. In further securitizing process, five questionnaire were rejected due to carelessly filled up and finally 305 taken in data analysis, which constitute $60 \%$ of response rate. The 305 number of participants in an opinion generating and perception related research is considered highly satisfactory and adequate. The sampled population was approached through professionally hired surveyors, to minimize the response biasness. The HEC website, HEC officials, registrar of respective universities and coordination offices were used as data sources and faculty was sampled through their provided information. The sampling methodology was based on geographically scattered universities in the three cities of Punjab: Lahore, Multan and Bahawalpur. Therefore, stratified random sampling procedure was used to approach the sampled faculty private and public universities.

The study uses descriptive statistics to report overall pattern of data and underlined response and behavioral pattern of sample in a specified situation. The inferential statistics are computed to test the hypothesis and draw certain conclusions based on sample statistics. Associations of demographical variables with satisfaction and stress are computed using cross tabulation. The frequency distribution is tabulated to portray the overall participation of sampled respondent. To explore the relationship, the Pearson product correlation coefficient is used. The Croan-bac 
Alpha score for the scale of occupational stress is 0.71 and for job satisfaction is 0.84 , which is quite satisfactory in survey related research and sufficient for the reliability and validity of research instrument by using Statistical Package for Social Sciences (SPSS).

\section{Results and Interpretation}

The study attempts to investigate the relationship between job satisfaction and occupational stress by administering the data of faculty members of higher education institutions in Pakistan. A representative sample of Pakistani universities is approached through survey and responses are taken on adapted study scale related to job satisfaction and occupational stress. The scales are modified to a small extent to ensure the language simplicity, construct understanding, variable relevancy and format to local settings.

\subsection{Respondents' Profile}

Table 1 and Table 2 shows the demographic information of university teachers regarding cadre of job, work experience, nature of job, gender age, and sector of university.

\subsection{Correlations between Occupational Stress and Job Satisfaction}

To test the null hypothesis, as there is no significant association between job satisfaction and occupational stress table 3 is computed. Based on given statistics, the $\mathrm{H}_{01}$ is not rejected and results show insignificant relationship between occupational stress and job satisfaction. In order to look further into relationship between occupational stress and job satisfaction across the various demographical and satisfaction variables, following tables are computed.

\subsection{Correlation between Occupational Stress and Overall Job Satisfaction across the Selected Demographical} Variables

Table 4 computes correlation between occupational stress and overall job satisfaction across the type of organization as private and public. The correlation coefficient " $\mathrm{r}$ " is equal to -0.435 which is significantly $(\mathrm{P}=.00<0.05)$ different from zero. The correlation indicates a negative relationship between the occupational stress and overall job satisfaction in faculty members of Private Universities. For Public Universities, the correlation coefficient " $\mathrm{r}$ " is equal to .091 which is not significantly $(\mathrm{P}=.17>0.05)$ different from zero. The correlation statistics indicate that there is no relationship between the occupational stress and overall job satisfaction in faculty members of Public Universities.

The correlation between occupational stress and overall job satisfaction is computed across both genders (Table 5). The correlation coefficient " $\mathrm{r}$ " is equal to -0.033 which is not significantly $(\mathrm{P}=.66>0.05)$ different from zero. The correlation statistics indicate that there is no relationship between the occupational stress and overall job satisfaction in the case of male faculty members of universities. Regarding female, the correlation coefficient " $\mathrm{r}$ " is equal to 0.035 which is not significantly $(\mathrm{P}=.70>0.05)$ different from zero. The correlation indicates that there is no relationship between the occupational stress and overall job satisfaction in female faculty members of universities.

To test the hypothesis that there is a correlation between occupational stress and overall job satisfaction across the job cadre table 6 is calculated. The correlation coefficient " $\mathrm{r}$ " is equal to -0.101 which is not significantly $(\mathrm{P}=.2>$ 0.05 ) different from zero. The correlation indicates that there is no relationship between occupational stress and overall job satisfaction in the lecturers of universities. Regarding assistant professor, the correlation coefficient " $\mathrm{r}$ " is equal to -0.207 which is significantly $(\mathrm{P}=.06<0.1)$ different from zero. The correlation indicates a negative relationship between the occupational stress and overall job satisfaction in assistant professors of the universities at $90 \%$ level of confidence.

Regarding associate professors, the correlation coefficient " $\mathrm{r}$ " is equal to 0.468 which is significantly $(\mathrm{P}=.01<0.05)$ different from zero. The correlation indicates a positive relationship between the occupational stress and overall job satisfaction in associate professors of the universities at 95\% level of confidence. Regarding professors, the correlation coefficient " $\mathrm{r}$ " is equal to 0.201 which is not significantly $(\mathrm{P}=.31>0.05)$ different from zero. The correlation indicates that there is no relationship between the occupational stress and overall job satisfaction in case of professors of universities.

To measure the correlation between occupational stress and overall job satisfaction across the age groups table 7 is computed. Regarding age bracket of $20-30$, the correlation coefficient " $\mathrm{r}$ " is equal to -0.243 which is significantly (P $=.02<0.05$ ) different from zero. The correlation indicates a negative relationship between the occupational stress and overall job satisfaction in faculty member of universities having age 20-30 years at 95\% level of confidence. Regarding other age brackets, there is no significant association found between occupational stress and overall job satisfaction in any of them. 
To test the hypothesis that there is no correlation between occupational stress and overall job satisfaction across the years of experience table 8 is formulated. Regarding $0-3$ years of experience, the correlation coefficient " $\mathrm{r}$ " is equal to -0.221 which is significantly $(\mathrm{P}=.02<0.05)$ different from zero. The correlation indicates a negative relationship between the occupational stress and overall job satisfaction in faculty members of universities having experience up to 3 years at $95 \%$ level of confidence. Regarding 4-12 years' experience, the correlation coefficient " $\mathrm{r}$ " is equal to -0.152 which is significantly $(\mathrm{P}=0.1)$ different than zero. The correlation indicates a negative relationship between the occupational stress and overall job satisfaction in faculty member of universities having experience 4-12 years at $90 \%$ level of confidence. Regarding 13-20 years of experience, the correlation coefficient " $\mathrm{r}$ " is equal to 0.814 which is not significantly ( $\mathrm{P}=0.23>0.05$ ) different than zero. The correlation indicates no relationship between the occupational stress and overall job satisfaction in faculty member of universities having experience 13-20 years. Regarding experience more than 20 years, the correlation coefficient " $\mathrm{r}$ " is equal to 0.322 which is significantly $(\mathrm{P}=0.05)$ different than zero. The correlation indicates a positive relationship between the occupational stress and overall job satisfaction in faculty members of universities having experience of 21 years and above at 95\% level of confidence.

To analyze the correlation between occupational stress and overall job satisfaction across the nature of job like visiting, contract and permanent table 9 is computed. The null hypothesis is not rejected in case of three variables and statistics of table 9 indicates insignificant relationship between occupational stress and overall job satisfaction in faculty members of universities; visiting, contract or having permanent job.

\section{Conclusions}

The following finding out of the analysis of descriptive and inferential statistics:

1) The Pearson correlation (Table 3) is applied to test significance of relationship between job satisfaction and overall occupational stress of faculty members of universities. According to the table statistics, there is no significant relationship found between job satisfaction and overall occupational stress. The results lead to the no rejection of $\mathrm{Ho}_{1}$. The further analysis of relationship across the various demographical variables may reveal statistically significant relationship between related items.

2) Table 4 computes correlation between occupational stress and overall job satisfaction across the type of organization as private and public. In case of private universities, significant correlation (-0.435) is found, which led to the rejection of $\mathrm{Ho}_{1.1}$ at $95 \%$ confidence level. The correlation indicates an inverse relationship between the occupational stress and overall job satisfaction in faculty members of private universities. The correlation statistics (Table 4) indicate that there is no relationship between the occupational stress and overall job satisfaction in faculty members of public universities, which led to the no rejection of $\mathrm{Ho}_{1.2}$ at $95 \%$ confidence level.

3) Table 5 computes correlation between occupational stress and overall job satisfaction across the gender. The correlation statistics indicate no relationship between the occupational stress and overall job satisfaction in case of both male and female faculty members of universities. The results confirm no rejection of $\mathrm{Ho}_{1.3} \mathrm{Ho}_{1.4}$ at $95 \%$ confidence level.

4) The analysis of correlation (Table 6) tests the relationship between job satisfaction and occupational stress across the cadre of universities teachers. The statistics support the rejection of $\mathrm{Ho}_{2.1} \mathrm{Ho}_{2.2}$ at $90 \%$ and at $95 \%$ confidence level respectively. The results inverse relationship of job satisfaction and occupational stress in case of assistant professors and positive relationship in case of associate professors. The insignificant relationship between job satisfaction and occupational stress is found in case of lecturers and professors, which led to not rejection of $\mathrm{Ho}_{2}$ and $\mathrm{Ho}_{2.3}$.

5) Table 7 outlines the correlation statistics between occupational stress and overall job satisfaction across the age groups ranging from 20 to above 60 years. The results of 20-30 years old faculty showed inverse relationship between occupational stress and overall job satisfaction, which led to the rejection of $\mathrm{Ho}_{3}$ at $95 \%$ confidence level. While in case of age brackets; 31-40, 41-50, 51-60 and above 60 years, the relationship is found insignificant 95\% confidence level, which led to the acceptance of $\mathrm{Ho}_{3.1}, \mathrm{Ho}_{3.2}, \mathrm{Ho}_{3.3}$ and $\mathrm{Ho}_{3.4}$ respectively. This analysis shows that in young age university teachers are more sensitive to the occupational stress and job satisfaction.

6) The correlation analysis (Table 8) measures relationship between job satisfaction and occupational stress across the different periods of experience of faculty members in higher education. The results reveal significantly inverse relationship in case of up to 3 and 4-12 years of experienced faculty and significantly direct relationship in case of above 21 years of experienced faculty. The insignificant relationship is found in case of faculty 
having 13-20 years experiences. The results led to the rejection of $\mathrm{Ho}^{16}, \mathrm{Ho}_{4.1}$ and $\mathrm{Ho}_{4.3} 95 \%, 90 \%$ and $95 \%$ confidence level and acceptance of $\mathrm{Ho}_{4.2}$ at $95 \%$ confidence level respectively.

7) No significant relationship (Table 9) is found between the occupational stress and overall job satisfaction in faculty members of universities across the nature of job; visiting, contract and permanent. The results led the not rejection of $\mathrm{Ho}_{5}, \mathrm{Ho}_{5.1}$ and $\mathrm{Ho}_{5.2}$.

\section{Limitations and Delimitations of the Study}

The study is limited to the sampled universities of Punjab province, which excludes institutions of higher education of other provinces of Pakistan and areas like federal territory, Azad Jammu \& Kashmir, Quetta and Karachi. The representative sample also delimits the researcher for wide coverage of views and to the faculty members of universities only. The time and budget were among the other constraints, which limited the scope and subject coverage of the research. The universe of the research is still less documented, which may deviate to some extent from the characteristics of sampled respondents. The secondary data in the context of Pakistan, related to subject is not available, which undermines literature contribution of this perspective.

\section{Future Research}

The study attempted a detail analysis of empirical investigation and secondary research findings under limited scope, period and sample. The analysis identifies number of issues, should be researched by the academicians in future. This study has collected the views of faculty of the universities, locate Punjab province of Pakistan. In future other provinces could be sampled in Pakistan or other countries to enhance the generalization of the findings. The management perspective also could be added along with faculty universities. The future research should also investigate the causes of low satisfaction and over stress in universities teachers. The future research also should incorporate the qualitative method of inquiry along with quantitative survey. The other scales of satisfaction and stress may reveal more significant insights of the phenomena, if used in future research.

\section{References}

Arnold, J. H., \& Feldman, C. (1986). Organizational behaviour. New York: McGraw Hill.

Bartlett, D. (1988). Stress: Perspectives and processes. Buckingham: Open University Press.

Berger, H. J. (1981). Burnout: How to beat the high cost of success. New York: Bantam Books.

Duke, S. D. (1990). Teaching - An introduction. New York: McGraw Hill.

Fatma, K. (2003). Employee satisfaction in higher education: the case of academic and administrative staff in Turkey. Career Development International, 8(7).

Fleet, D. D. (1991). Behaviur in organization. New Jersy: Houghton Mifflin Company.

Greenberg Jerrold, S. (2002). Comprehensive Stress Management. New York: McGraw Hill.

Moorhead, G., \& Griffin, R. W. (2001). Organizational Behaviors Managing people and Organizations (5th ed.). New York: Houghton Mifflin Company.

Robbins, S. P. (1996). Organizational behaviour. New York: Prentice Hall.

Rocca, A. D., \& Kostanski, M. (2001). Burnout and job satisfaction amongst Victorian, Secondary school teachers: a comparative look at Contract and permanent employment. Paper presented at the conference on Teacher education: change of heart, mind and action.

Sattar, K., \& Jamil, M. (2004). A study of effects of stress on job satisfaction among elementary head teachers. University of the Punjab, Lahore.

Spector, P. E. (1997). Job satisfaction: application, assessment, cause, and consequence. Thousand Oaks, CA: Sage. Togia A Koustelios, \& Tsigilis N. (2005). Job satisfaction among Greek librarians. Library and Inf. Sci. Res, 26(3).

Truell, A. D., William. T, \& Joyner, R. L. (1998). Job Satisfaction Among Community College Occupational-Technical Faculty. Community college journal of research \& practice, 22(2). http://dx.doi.org/10.1080/1066892980220202

Williams, M. L., \& Wiatrek, D. (1986). An Analysis of the Communication Systems of Part and Full-Time Instructors in Community Colleges. Paper presented at the International Communication Association.

Wisniewski, W. (1990). The Job Satisfaction of Teachers in Poland. Comparative education, 26(2/3).

Wu, V., Short, Paula M (1996). The Relationship Of Empowerment To Teacher Job Commitment And Job Satisfaction. Journal of Instructional Psychology, 23(1). 
Table 1. The Frequency and Percentage of Respondents’ Across the Selected Demographic Variables

\begin{tabular}{lll}
\hline Characteristic & N & \% \\
\hline Cadre of job & 163 & 53.4 \\
Lecturer & 81 & 26.6 \\
Assistant Professor & 33 & 10.8 \\
Associate Professor & 28 & 9.2 \\
Professor & & \\
Experience & 106 & 34.8 \\
$0-3$ & 118 & 38.7 \\
$4-12$ & 44 & 14.4 \\
$13-20$ & 37 & 12.1 \\
21 \& Above & & \\
Nature of job & 220 & 72 \\
Permanent & 75 & 25 \\
Contract & 10 & 3 \\
Visiting Faculty & & \\
\hline
\end{tabular}

Table 2. The Frequency and Percentage of Respondents’ Across the Selected Demographic Variables

\begin{tabular}{lll}
\hline Characteristic & N & \% \\
\hline Gender & 185 & \\
Male & 120 & 60.7 \\
Female & & 39.3 \\
Organizational Type & 229 & \\
Public Sector & 76 & 75.1 \\
Private Sector & & 24.9 \\
Age & 99 & \\
$20-30$ & 101 & 32 \\
$31-40$ & 65 & 33 \\
$41-50$ & 33 & 21.3 \\
$50-60$ & 7 & 10.8 \\
$61-m o r e$ & & 2.3 \\
\hline
\end{tabular}

Table 3. Correlations between Overall Occupational Stress and Overall Job Satisfaction

\begin{tabular}{lll}
\hline & & Overall Job Satisfaction \\
\hline Overall Occupational Stress & Pearson Correlation & -0.005 \\
& Sig. (2-tailed) & 0.931 \\
& $\mathrm{~N}$ & 305 \\
\hline
\end{tabular}


Table 4. Correlation between Occupational Stress and Overall Job Satisfaction across the Type of Organization

\begin{tabular}{lll}
\hline Demographic Variables & $\mathrm{r}$ & Sig. \\
\hline Private & -0.435 & 0.00 \\
Public & 0.091 & 0.17 \\
\hline
\end{tabular}

Table 5. Correlation between Overall Occupational Stress and Overall Job Satisfaction across the Gender

\begin{tabular}{lll}
\hline Demographic Variables & $\mathrm{r}$ & Sig. \\
\hline Male & -0.033 & 0.66 \\
Female & 0.035 & 0.70 \\
\hline
\end{tabular}

Table 6. Correlation between Overall Occupational Stress and Overall Job Satisfaction across the Job Cadre

\begin{tabular}{lll}
\hline Demographic Variables & $\mathrm{r}$ & Sig. \\
\hline Lecturer & -0.101 & 0.20 \\
Assistant Professor & -0.207 & $0.06^{* *}$ \\
Associate Professor & 0.468 & $0.01^{*}$ \\
Professor & 0.201 & 0.31 \\
\hline
\end{tabular}

* Significant at 95\% confidence interval

** Significant at $90 \%$ confidence interval

Table 7. Correlation between Overall Occupational Stress and Overall Job Satisfaction across the Age Groups

\begin{tabular}{lll}
\hline Demographic Variables & $\mathrm{r}$ & Sig. \\
\hline $20-30$ & -0.243 & $0.02^{*}$ \\
$31-40$ & 0.025 & 0.80 \\
$41-50$ & 0.172 & 0.17 \\
$51-60$ & -0.061 & 0.74 \\
60- Above & -0.098 & 0.83 \\
\hline
\end{tabular}

Table 8. Correlation between Overall Occupational Stress and Overall Job Satisfaction across the Years of Experience

\begin{tabular}{lll}
\hline Demographic Variables & $\mathrm{r}$ & Sig. \\
\hline $0-3$ & -0.221 & $0.02^{*}$ \\
$4-12$ & -0.152 & 0.10 \\
$13-20$ & 0.184 & 0.23 \\
21 \& above & 0.322 & $0.05^{*}$ \\
\hline
\end{tabular}

* Significant at 95\% confidence interval

** Significant at $90 \%$ confidence interval

Table 9. Correlation between Overall Occupational Stress and Overall Job Satisfaction across the Nature of job

\begin{tabular}{lll}
\hline Demographic Variables & $\mathrm{r}$ & Sig. \\
\hline Visiting & -0.179 & 0.62 \\
Contract & -0.120 & 0.30 \\
Permanent & 0.022 & 0.74 \\
\hline
\end{tabular}




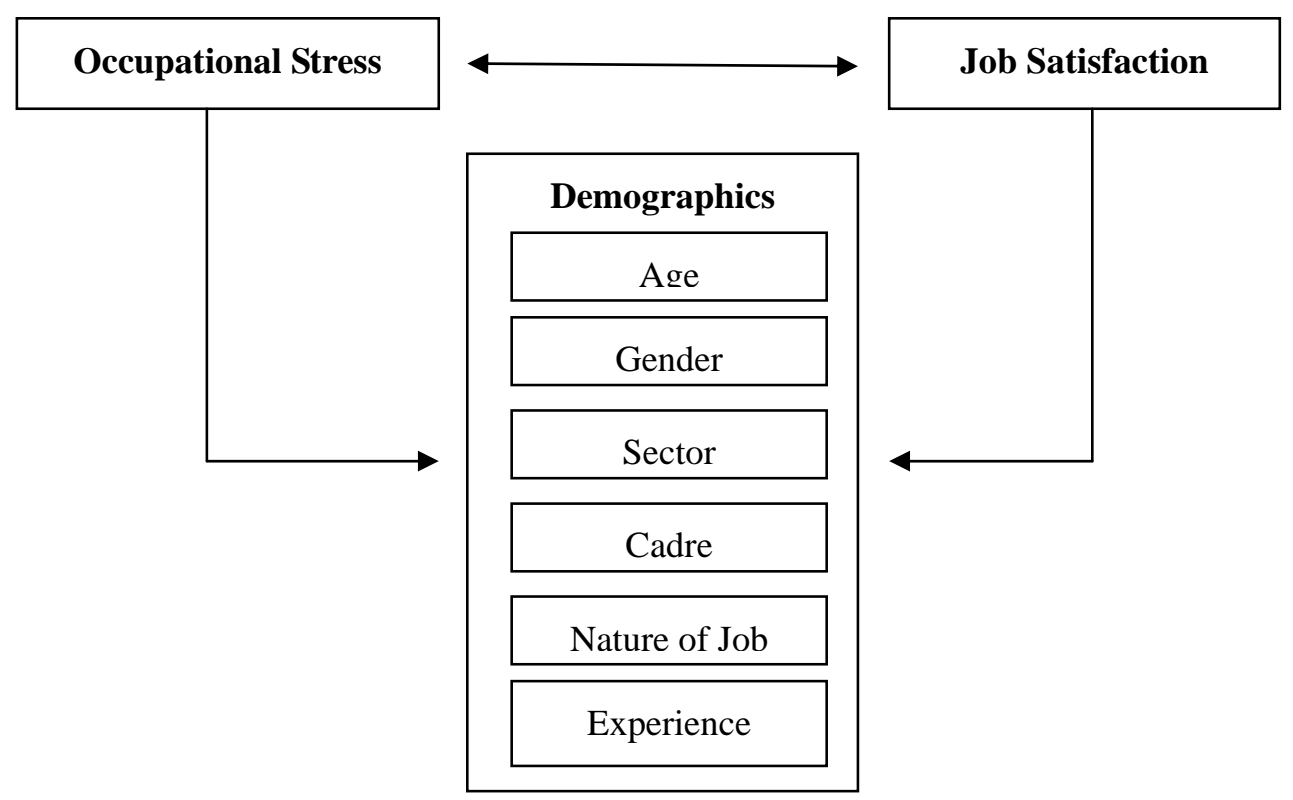

Figure 1. Relationship between Occupational Stress and Job Satisfaction 